\title{
O ENSINO DE CLIMATOLOGIA NO VALE DO JEQUITINHONHA
}

\author{
TEODORO, Pacelli Henrique Martins - pacelli.teodoro@ufvjm.edu.br \\ Universidade Federal dos Vales do Jequitinhonha e Mucuri / UFVJM
}

\begin{abstract}
RESUMO: Na Universidade Federal dos Vales do Jequitinhonha e Mucuri, o ensino de climatologia está presente como unidade curricular no eixo da área de concentração do Bacharelado em Humanidades, sendo obrigatória na transição deste para a Licenciatura em Geografia. Por seus conteúdos básicos destoarem, até então, dos habitualmente aprendidos num curso de Humanidades, a climatologia apresenta uma resistência inicial por parte do corpo discente, que estimula receios, antecipa dificuldades e aumenta a retenção acadêmica, a qual pode potencializar a evasão ou reopção de curso profissionalizante. Por isto, o objetivo deste artigo é revisar o processo de ensinoaprendizagem na área da Climatologia Geográfica e recomendar ações didáticas capazes de dinamizá-lo e, assim, desenvolvê-lo com êxito. Durante sete períodos letivos (do 2014/2 ao 2017/2), o planejamento da unidade curricular passou por contínuas mudanças, fundamentadas na autorreflexão docente a partir de uma vasta bibliografia de Didática, que pôde agregar experiências diretas com as Tecnologias Digitais de Informação e Comunicação (por exemplo, circulação atmosférica interativa, previsões instantâneas do tempo, animações audiovisuais por meio do Ambiente Virtual de Aprendizagem), instrumentos meteorológicos, trabalhos de campo e gráficos de análise rítmica. Aliados à busca por métodos criativos, inovadores e participativos, esses recursos possuíam a finalidade de reduzir a abstração dos conteúdos previstos e, também, contextualizar temporo-espacialmente cada indivíduo com o cotidiano, a fim de produzir sentidos particulares na educação. Do semestre inicial ao final já mencionados, os dados registrados sintetizam, de modo geral, a melhoria progressiva na situação das turmas e sustentam parte dos resultados alcançados: retenção por nota de $33,3 \%$ a zero; retenção por nota e frequência de $56,7 \%$ a $25 \%$; e aprovação de $10 \%$ a $75 \%$. E para além disso, as avaliações institucionais e informais a respeito da BHU416 têm demonstrado maior interesse dos discentes nas temáticas climáticas e, também, desfeito a demasiada ansiedade concebida antes mesmo do momento da matrícula.
\end{abstract}

PALAVRAS-CHAVE: didática, retenção acadêmica, Climatologia Geográfica, práticas contextualizadas, Minas Gerais.

\section{THE TEACHING OF CLIMATOLOGY IN JEQUITINHONHA VALLEY}

ABSTRACT: At the Federal University of Jequitinhonha and Mucuri Valleys, the teaching of climatology is present as a curricular unit in the Bachelor of Human Sciences concentration area axis, being required in the course of the Degree in Geography. For its basic contents disrupt of the others usually studied at Humanities course, climatology presents an initial resistance by students, which stimulates apprehension, anticipates difficulties and increases academic retention, which can enable dropout or reopening of vocational course. Therefore, the objective is to revise teaching-learning process in the Geographical Climatology area and recommend didactic actions useful of invigorate itself, thus, to develop it successfully. For seven semesters (2014/2 to 2017/2), the course planning underwent continuous changes, based on teacher self-reflection since an extensive Didactics bibliography, which provided direct experiences with Digital Information and Communication Technologies (for example, interactive atmospheric circulation, instantaneous weather forecasts, audiovisual animations through the Virtual Learning Environment), meteorological instruments, fieldwork and rhythmic analysis charts. Associated with the search for creative, innovative and participative methods, these resources had a purpose to decrease the contents abstraction and contextualizing temporary-spatially the students with their daily life individually, in order to produce particular meanings in the education. From the initial to the final semester, recorded data synthesize the progressive improvement in the classes' situations and sustain part of the obtained results: retention by grades from $33.3 \%$ to zero, retention by grades and frequency from $56.7 \%$ to $25 \%$ and approval from $10 \%$ to $75 \%$. In addition, the institutional and informal evaluations assessments about BHU416 have demonstrated the 
increased student interest about the climate themes and have undone the anxiety conceived before the enrollment

KEYWORDS: didactic, academic retention, Geographical Climatology, contextualized practices, Minas Gerais State.

\section{LA ENSEÑANZA DE CLIMATOLOGÍA EN EL VALLE DEL JEQUITINHONHA}

RESUMEN: En la Universidad Federal de los Valles del Jequitinhonha y Mucuri, la enseñanza de climatología está presente como unidad curricular en el eje del área de concentración del Bachillerato en Humanidades, siendo obligatoria en la transición de éste a la Licenciatura en Geografía. Por sus contenidos básicos divergen, hasta entonces, de los habitualmente aprendidos en un curso de Humanidades, la climatología presenta una resistencia inicial por parte del cuerpo discente, que estimula temores, anticipa dificultades y aumenta la retención académica, la cual puede potenciar la evasión o reopción de curso profesional. Por eso, el objetivo de este artículo es revisar el proceso de enseñanza-aprendizaje en el área de la Climatología Geográfica y recomendar acciones didácticas capaces de dinamizarlo y, así, desarrollarlo con éxito. Durante siete períodos lectivos (de 2014/2 al 2017/2), la planificación de la unidad curricular pasó por continuos cambios, fundamentados en la autorreflexión docente a partir de una vasta bibliografía de Didáctica, que pudo agregar experiencias directas con las Tecnologías Digitales de la Información y Comunicación (por ejemplo, circulación atmosférica interactiva, previsiones instantáneas del tiempo, animaciones audiovisuales a través del Entorno Virtual de Aprendizaje), instrumentos meteorológicos, trabajos de campo y gráficos de análisis rítmico. Aliados a la búsqueda de métodos creativos, innovadores y participativos, esos recursos tenían la finalidad de la reducción abstracta de los contenidos previstos y también de la contextualización del tiempo-espacio de cada individuo con lo cotidiano, a fin de producir sentidos particulares en la educación. En el semestre inicial al final ya mencionados, los datos registrados sintetizan, en general, la mejora progresiva en la situación de las clases y sustentan parte de los resultados alcanzados: retención por nota del $33,3 \%$ a cero; retención por nota y frecuencia del $56,7 \%$ al $25 \%$; y la aprobación del $10 \%$ al $75 \%$. Y además, las evaluaciones institucionales e informales sobre la BHU416 han demostrado un mayor interés por los discentes en las temáticas climáticas y también han deshecho la excesiva ansiedad concebida incluso antes del momento de la matriculación

PALABRAS CLAVE: didáctica, retención académica, Climatología Geográfica, prácticas contextualizadas, estado de Minas Gerais.

\section{INTRODUÇÃO}

Com princípio na ciência moderna e sua fragmentação do conhecimento, a Geografia é basicamente segmentada em duas grandes subáreas, uma Física e outra Humana. Além deste resistente entrave a ser urgentemente superado, principalmente em tempos que já se discutem estratégias epistemológicas para trabalharem conhecimentos compartimentados, ${ }^{1}$ o ensino de Geografia ainda é qualificado como conteudista, sem muito diálogo com o mundo exterior à sala de aula. Nisto, a climatologia acentua a abstração do ensino-aprendizagem por seus estudos atmosféricos, embora seja uma das especialidades geográficas mais influentes no dia a dia das pessoas, e desafia o tratamento conceitual de clima pelo paradigma do ritmo. Em meio a tudo isso, uma questão central permeia o presente artigo: como planejar um ensino de climatologia de modo a atender um curso de Humanidades, modalidade bacharelado, e, ao mesmo

\footnotetext{
${ }^{1}$ Por sua notoriedade acadêmica, educacional e até legal, a interdisciplinaridade expressa essa busca de como relacionar distintas disciplinas em torno de um só objeto - por exemplo, a questão ambiental e sua crise global emergente nas décadas de 1960 e 70 . Aliás, a consolidação ambiental na atual agenda internacional representa, como confirmaram Suertegaray e Nunes (2001), uma oportunidade promissora para o reencontro da Geografia Física com a Humana.
} 
tempo, sua transição para outro de Geografia, modalidade licenciatura, sem desconsiderar as particularidades típicas de um curso presencial e noturno numa universidade do interior de Minas Gerais?

Como campo de conhecimento científico com identidade própria, a climatologia remete-se ao estudo da espacialização dos elementos e fenômenos atmosféricos, bem como de sua evolução no decorrer do tempo (MENDONÇA; DANNI-OLIVEIRA, 2007). Ao se fundamentar no arcabouço teórico-metodológico do positivismo e neopositivismo, seu ensino costuma se limitar à postura empirista, naturalista e classificatória. Deste modo, os estudos climáticos tendem, a partir de sua origem no seio das ciências naturais, a descrever, enumerar e classificar quantitativamente a atmosfera terrestre, a favor de um ensino abstrato e descontextualizado, voltado à memorização de conteúdo. Mas a realidade apresentada vai para além do saber climático.

Para Callai (1995, p. 17), a Geografia Física é tida como mais científica no imaginário social quando comparada à Humana, por suas questões serem mais diretas, com objetos e métodos claramente definidos e dados nitidamente observáveis, e, por conseguinte, o empirismo geográfico é atendido de maneira plena; "esta dualidade não está, por certo, até hoje resolvida [...].". ${ }^{2}$ Esta dita Geografia aplicada é um produto pragmático de sua instrumentalização em meados do século $X X$, com a renovação de conhecimentos pelas geografias sistêmica, modelística e quantitativa (MORAES, 1983). E semelhante à climatologia, a Geografia Física transfere pesquisas sobre a dinâmica da natureza, com as relações sociais reduzidas a "atividades antrópicas", para um ensino conteudista a ser memorizado, muitas vezes sem sentido para o alunado.

No interior do estado de Minas Gerais, a Universidade Federal dos Vales do Jequitinhonha e Mucuri (UFVJM) se faz também presente no município de Diamantina, na região do Vale do Jequitinhonha, conhecida por seus contrastes paisagísticos, sua cultura típica e seu baixo dinamismo econômico. Num campus localizado na rodovia MGT 367, fora do perímetro urbano cerca de $8 \mathrm{~km}$ de sua área central, a Licenciatura em Geografia é, até então, um curso atrelado a um Bacharelado Interdisciplinar, na grande área do conhecimento de Humanidades. Em três anos, o aluno cursa anualmente o eixo da formação de base e complementar, o interdisciplinar e o das áreas de concentração (UFVJM, 2011), os quais proporcionam uma formação em torno da interdisciplinaridade e de diálogos entre componentes curriculares de várias áreas do conhecimento, na perspectiva da alta flexibilização curricular (BRASIL, 2010). Por ser um curso superior de graduação não profissionalizante, o Bacharelado em Humanidades pode ser complementado por outro curso na modalidade de licenciatura e, desta maneira, a Geografia constitui-se numa das opções, dentro do período de integralização curricular de mais dois anos.

Outros dados relevantes são as especificidades do público recebido pela UFVJM. Num diagnóstico recente de seu Núcleo Docente Estruturante (UFVJM, 2018a), a Licenciatura em Geografia atende um público com as seguintes características: a maioria é a primeira geração da família a ter acesso à universidade pública; por ser um curso presencial e noturno, grande parte tem

\footnotetext{
${ }^{2}$ A pouca integração da Geografia Física com a Humana deve-se a sua pouca ênfase teórica, o que consolidou uma compartimentação histórica dos estudos acerca da natureza pela dicotomia físicosocial (AMORIM; NUNES, 2006).
} 
vínculo empregatício no turno inverso; ${ }^{3}$ muitos discentes possuem sérias dificuldades para se adaptarem ao habitus acadêmico (rotinas de leitura, indagação, problematização e reflexão sistematizada), além de apresentarem graves problemas no domínio da língua portuguesa (dificuldades de leitura, interpretação, compreensão e redação textual, com desenvolvimento de ideias argumentativas articuladas); e parte significativa possui um perfil sociocultural interiorano, do espaço rural, com fortes estigmas sociais, que se difere bastante do perfil dos docentes, em sua maioria oriunda de grandes ou médios centros urbanos e formados em instituições de ensino superior já consolidadas. ${ }^{4}$

O ensino de climatologia está previsto no quinto período do Bacharelado em Humanidades, especificamente em seu eixo da área de concentração para a Geografia. Sob o código BHU416, esta unidade curricular é obrigatória na transição do mencionado bacharelado para a Licenciatura em Geografia, quando sua carga horária de 75 h é prontamente aproveitada. Em outras palavras, uma turma de quarenta e oito vagas pode abrigar discentes que tanto têm interesse em continuar seus estudos na Geografia quanto aqueles que possuem propósito de somente concluir seus estudos nas Humanidades, além daqueles em menor número de outros cursos (por exemplo, da Agronomia) ou que possuem algum entusiasmo midiático pela temática das mudanças climáticas. Diante desta diversidade, o planejamento da ação didática de uma especialidade que se integra como uma subdivisão das ciências naturais e exatas (Física) e humanas e sociais (Geografia) (MENDONÇA; DANNI-OLIVEIRA, 2007) torna-se um desafio a ser superado de modo reflexivo.

É notório que os conteúdos basilares da climatologia são destoantes dos comumente aprendidos num curso de Humanidades. E isto se agrava quando a situação anterior tende a permanecer: fragmentação física e humana entre as geografias; perspectiva empirista, naturalista e classificatória de fenômenos pela Geografia Física; ensino de Geografia conteudista e abstrato; e prioridade quantitativa na descrição da atmosfera com discussão rasa sobre sua interação terrestre, sem atentar à complexidade das relações sociais na produção do espaço. Logo, a climatologia configura-se, desde o início, como uma resistência por parte de uma turma tão diversa, pertencente a um curso noturno de uma universidade interiorana. Tal resistência estimula receios, antecipa dificuldades e aumenta a retenção acadêmica, a qual pode potencializar a evasão ou reopção de curso profissionalizante.

Como alternativa à problemática apontada, a Didática possui importante papel ao estudar o processo de ensino, pois pode proporcionar meios para que alunos assimilem conhecimentos e desenvolvam habilidades de forma ativa, para Libâneo (1990). Mas este aprimoramento das capacidades cognitivas só se torna possível pelo trabalho docente em mediar a relação cognoscitiva entre aluno e matéria de ensino. $E$, nisto, a organização da atividade pedagógica revela-se como essencial, por meio da intermediação dos objetivos de ensino e sócio-políticos e da seleção de conteúdos e métodos. "Ora, não é suficiente dizer que os alunos precisam dominar os conhecimentos; é necessário dizer como

\footnotetext{
3 "Esta realidade interfere na disponibilidade de tempo para se dedicar aos estudos, participação em eventos, projetos de pesquisa etc. e, inclusive, para a realização ou acompanhamento de atividades referente às práticas como componente curricular;" (UFVJM, 2018a, p. 34).

4 "Essas diferenças socioculturais constituem-se como um desafio na construção de relações profissionais e sociais dialógicas e horizontais, que fortaleçam a integração, o respeito mútuo, os processos de ensino-aprendizagem e, principalmente, a superação de estigmas." (UFVJM, 2018a, p. 34-35, grifo nosso).
} 
fazê-lo, isto é, investigar objetivos e métodos seguros e eficazes para a assimilação dos conhecimentos." (LIBÂNEO, 1990, p. 54).

Nesse processo educacional, a identidade profissional, quando adaptada ao contexto social, político e histórico, permite o desenvolvimento críticoreflexivo e investigativo da prática docente, conforme Maia et al. (2009), para sua constante reconstrução e ressignificação pelo movimento de ação-reflexão, reflexão-ação. E a partir desta formação reflexiva, a Climatologia Geográfica surgiu como resposta para buscar um ensino dinâmico e contextualizado que proporcione conhecimentos sócio-naturais e habilidades criativas, reforçando a importância de "a construção de um raciocínio geográfico que possibilite a formação de sujeitos capazes de ler e transformar o mundo em que vivem [...]." (GIROTTO, 2015, p. 233).

Se o objeto de estudo da Geografia é o espaço e os conteúdos espaciais revelam movimentos intrínsecos entre sociedade e natureza, segundo Santos (1996), o ensino de Geografia também deve abranger o espaço e a interação de suas dinâmicas sociais e naturais, em conexão à vida cotidiana numa relação interescalar. $\mathrm{E}$ isto requer o desenvolvimento de novas práticas pedagógicas aliadas a situações reais, diárias e comuns, visto que são fundamentais para a formação de um cidadão crítico, capaz de analisar e formar opinião de maneira autônoma, e participante ativo na sociedade. Para esta educação emancipatória e humana, os conteúdos tratados na climatologia (especialmente na Geográfica) são espontaneamente passíveis de serem inseridos no dia a dia, afinal, atingem direta ou indiretamente a vida de cada pessoa, seja na saúde, na cidade, na agricultura. Por isto, o objetivo deste artigo é revisar o processo de ensinoaprendizagem na área da Climatologia Geográfica e recomendar ações didáticas capazes de dinamizá-lo e, assim, desenvolvê-lo com êxito.

\section{PROCEDIMENTOS METODOLÓGICOS}

Do segundo semestre letivo do ano de 2014 ao segundo do de 2017, o planejamento da unidade curricular em questão passou por revisões regulares, com base na discussão teórica sobre Didática e Geografia e revisão bibliográfica sobre ensino de climatologia e Climatologia Geográfica. Num processo mental de análise, reflexão e previsão, a ideia foi maximizar a correlação dos conteúdos climáticos e geográficos, bem como esboçar uma ação didática condizente com a escala regional e realidade acadêmica. Como ponto de partida, definiu-se o objetivo geral da BHU416, com propósitos amplos de compreender a dinâmica climática relacionada notoriamente com a produção do espaço e, assim, inferir o clima como fenômeno geográfico.

Essa etapa mental recorreu-se ao caráter questionador, crítico e reflexivo da profissão docente, como forma de privilegiar a criatividade interna e não só a reprodução externa. E a formação do professor reflexivo auxiliou o referido momento por basear-se numa epistemologia da prática, isto é, valoriza a prática profissional na construção de conhecimento, por meio de sua reflexão, análise e problematização, e no reconhecimento do conhecimento implícito, presente apenas na ação, segundo Pimenta (2006). A prática reflexiva pressupõe, assim, "[...] entendê-la como atitude que possibilita ao professor voltar-se sobre si mesmo, sobre sua prática e sobre sua ação de forma analítica, a fim de identificar lacunas e, a partir delas, repensar o seu fazer docente." (MAIA et al., 2009, p. 42). 
E, por fim, Alves (2008) complementou o processo reflexivo adotado ao alertar o resumo da educação em duas palavras: ferramentas e brinquedos. Ao passo que a primeira refere-se a conhecimentos que resolvem problemas do dia a dia, a segunda condiz com todas aquelas coisas que dão prazer e alegria à alma, sem utilidade como ferramentas. "Assim, todo professor, ao ensinar, teria que perguntar: 'isso que vou ensinar é ferramenta? É brinquedo?'. Se não for, é melhor deixar de lado." (ALVES, 2008, p. 32).

Como resultado material, o plano de ensino refletiu um produto vivo em (re)elaboração, mas sempre adequado às seguintes características: a) coerência e unidade entre objetivos, conteúdos, métodos e avaliações; b) continuidade e sequência das atividades pedagógicas, do começo ao fim; c) flexibilidade, com possíveis reajustes às situações não previstas; d) objetividade e funcionalidade ao atender interesses e necessidades dos alunos na assimilação de conhecimentos; e e) precisão e clareza, por meio de linguagem simples e exata (HAYDT, 2006). Salienta-se que tanto a ementa quanto as bibliografias básicas e complementares, previstas no Projeto Pedagógico de Curso, foram atendidas dentro das normas legais da Universidade. E com base no ementário, esforçouse selecionar conteúdos, que representam aquele conjunto de conhecimentos e habilidades, em vista à correspondência com os objetivos pedagógicos e sociais; o caráter científico (fatos, conceitos, ideias, métodos modernos) e sistemático (lógica interna entre si); a relevância social, pela incorporação de experiências populares e vivências cotidianas para aplicações práticas; e a acessibilidade e solidez, ou seja, a compatibilidade com o desenvolvimento mental do alunado para uma assimilação sólida e duradoura, de acordo com Libâneo (1990).

No ato didático, as aulas foram lecionadas pelo método verbal (dizer), com o início da construção do saber por múltiplas formas orais para expor ou interrogar alunos sobre certo assunto (exposição, explicação, diálogo, debate); intuitivo (mostrar), de modo a obter conhecimentos gerais por sentidos, memória, inteligência (texto escrito, audiovisual, demonstração); e ativo (fazer), da percepção sensorial, realidade, vivência, experiência à construção de conhecimentos (trabalho em grupo, estudo de caso) (HAYDT, 2006). Para tal, os recursos e materiais didáticos utilizados também tiveram que ser diversificados, para apoiar as práticas de ensino e contribuir com o aprendizado dos conteúdos propostos: artigos e periódicos científicos, capítulos e livros; entrevistas e glossário; documentários e palestras; informações da comunicação de massa, prosas e letras de música; figuras, fotos, diagramas, tabelas e quadros; slides e quadro branco sobrepostos e interagidos com o uso de pincéis; apostila própria e ilustrativa; representações materiais em escala reduzida da Terra e do sistema solar; Ambiente Virtual de Aprendizagem; sítios eletrônicos interativos com circulação atmosférica e previsões instantâneas do tempo; animações audiovisuais; instrumentos meteorológicos e trabalhos de campo; gráficos de análise rítmica.

Particularmente, as Tecnologias Digitais de Informação e Comunicação (TDIC) se mostraram como uma solução para simular fenômenos atmosféricos, por sua qualidade de movimentar e até interagir objetos em tela. Seja em sala de aula ou na Plataforma Moodle (Ambiente Virtual de Aprendizagem), o uso destas tecnologias permitiu, por exemplo, trazer o estado momentâneo da atmosfera sob o município de Diamantina minutos antes de cada aula, por meio de Windy, ${ }^{5}$ com explanações teórico-práticas entre a circulação atmosférica e os

\footnotetext{
${ }^{5}$ Disponível em: <https://www.windy.com>. Acesso em: 4 ago. 2018.
} 
elementos climáticos; complementar tais explicações com previsões do tempo, disponibilizadas pelo Centro de Previsão de Tempo e Estudos Climáticos (CPTEC) e Instituto Nacional de Pesquisas Espaciais (INPE); ${ }^{6}$ e aprofundar o ensino com animações do canal Climatempo Meteorologia (em especial, playlist "Explicando o Tempo") e vídeos educacionais do CPTEC/INPE. ${ }^{7}$

O planejamento dos campos partiu de três critérios principais: aproveitar o horário destinado às aulas da BHU416, pois atividades extraturnos costumam não contemplar todos; selecionar conteúdos com baixo desempenho da turma; e preferir o trabalho em grupos. Deste jeito, a proposta foi registrar elementos climáticos e fatores geográficos no Campus JK, associada à exposição teórica e o manejo prático dos instrumentos meteorológicos disponíveis no patrimônio do curso de Geografia: Anemômetro Digital Instrutherm (AD-250), Multifuncional Digital Altímetro ZW (ZD-2028/6-1), Pluviômetro Incoterm (150 mm) e Termohigrômetro Digital Victor. Além destes, o GPS Portátil Garmin (GPSmap 76CSx) foi acrescentado aos roteiros de campo, para identificar a localização exata dos pontos mensurados. Ao longo dos trajetos, cada aluno se responsabilizou por anotar dados medidos ou informações da paisagem, que formaram a estrutura básica da tarefa posterior: uma representação gráfica da pesquisa de campo em papel milimetrado A3, como forma de sistematização coletiva.

E a análise rítmica constituiu numa proposta metodológica para somar a gênese dos fenômenos atmosféricos aos estudos dos elementos fundamentais do clima (MONTEIRO, 1971). Dados meteorológicos das estações automáticas do Instituto Nacional de Meteorologia, ${ }^{8}$ imagens por satélite do CPTEC/INPE ${ }^{9} \mathrm{e}$ cartas sinóticas do Centro de Hidrografia da Marinha ${ }^{10}$ forneceram, quando alinhados e examinados em conjunto, representações cronológicas do ritmo climático, elaboradas individualmente em papel milimetrado A3. E para situar os sujeitos na realidade, a escala de análise padrão é o município de Diamantina numa semana anterior à prática, para torná-la num período de observação sensível por cada um antes de sua investigação científica.

Já as avaliações partiram da teoria de inteligências múltiplas, baseada, a partir da psicologia desenvolvimentista e neuropsicologia, na capacidade do ser humano de desenvolver inteligências diferentes e independentes entre si, mas geralmente combinadas nas atividades razoavelmente complexas (MAIA et al., 2009). Desta forma, as propostas de avaliação visaram desenvolver e valorizar as inteligências diferenciadas daquela turma diversa, por meio das faculdades humanas em linguística (discussões em classe, atividades a distância, provas), lógico-matemática (provas), espacial (pesquisa de campo, análise rítmica) e interpessoal (seminário).

\footnotetext{
${ }^{6}$ Disponível em: <https://tempo.cptec.inpe.br>. Acesso em: 4 ago. 2018.

${ }^{7}$ Disponíveis em: <https://www.youtube.com/user/climatempo>;

<http://videoseducacionais.cptec.inpe.br>. Acessos em: 4 ago. 2018.

7 Disponível em: <http://www.inmet.gov.br/portal/index.php?r=estacoes/estacoesAutomaticas > .

${ }^{8}$ Disponível em: <http://www.inmet.gov.br/portal/index.php?r=estacoes/estacoesAutomaticas > . Acesso em: 11 ago. 2018.

${ }^{9}$ Disponível em: <http://satelite.cptec.inpe.br/home/index.jsp>. Acesso em: 11 ago. 2018.

${ }^{10}$ Disponível em: <https://www.marinha.mil.br/chm/dados-do-smm-cartas-sinoticas/cartassinoticas>. Acesso em: 11 ago. 2018.
} 


\section{RESULTADOS E DISCUSSÃO}

Para repensar a aula e melhorar a docência, Maseto (2003) propôs uma mudança na ênfase do paradigma fundante do ensino superior: do ensino para a aprendizagem. Ao invés de ter o papel exclusivo de transmitir informações e experiências consolidadas, com a finalidade do aprendiz as reter, absorver e reproduzir em determinadas etapas avaliativas, o professor deve ser o mediador do processo pedagógico, quando questiona e seleciona seus conhecimentos assimilados e suas experiências vividas para o desenvolvimento da formação profissional dos alunos.

O atual plano de ensino da BHU416 possui dois grandes momentos de aprendizado: um em climatologia e Geografia, outro na Climatologia Geográfica. $\mathrm{Na}$ primeira oportunidade, os conteúdos básicos da climatologia são priorizados por serem imprescindíveis ao objetivo geral, ${ }^{11}$ mas sempre correlacionados aos conhecimentos geográficos, como meio de aproximar a unidade curricular ao próprio curso, o Bacharelado em Humanidades. E na segunda, esta correlação torna-se mais clara pela persistência em inter-relacionar as geografias Física e Humana, sobretudo a partir das relações de poder e suas diferenciações geográficas que envolvem a produção do espaço. ${ }^{12}$ Essa estrutura dual tenciona agregar a perspectiva teórica, social e complexa à climatologia, visto que é uma especialidade tradicional da Geografia Física.

Concentradas em cinco horas consecutivas (das $18 \mathrm{~h}$ às $23 \mathrm{~h}$ ) num dia por semana, as aulas são devidamente adaptadas ao perfil comum do alunado. Num ambiente de aprendizagem participativo e com respeito mútuo, ${ }^{13}$ debates coletivos sobre a função de uma universidade pública, gratuita e de qualidade, junto à importância urgente de garanti-la, sustentam e permeiam o processo de ensino-aprendizagem. Para atenuar o trabalho extraclasse, as leituras indicadas e disponibilizadas em formato digital não são obrigatórias, sendo parcialmente incluídas nas aulas expositivas e discursivas e, assim, reforçadas como leituras complementares. Ainda, uma hora a cada semana é legalmente destinada ao ensino a distância para permitir o início das aulas às $19 \mathrm{~h}$, compatibilizando eventuais atividades laborais com o ensino superior. E para trazer os alunos ao universo indagativo e reflexivo, situações cotidianas, estudos de caso, questões problematizadoras são alguns dos artifícios coletivos para contextualizar os conteúdos e estabelecer uma ponte entre conhecimentos gerais e científicos.

E, como já aludidas, as avaliações são diversificadas para contemplar e reconhecer as inteligências múltiplas. Atividades orais ou escritas, individuais ou coletivas, em classe ou extraclasse são mescladas, distribuídas e pontuadas, de maneira equilibrada, durante todo o semestre letivo, com prazos razoáveis para executar cada tarefa avaliativa.

\footnotetext{
11 Tempo e clima, meteorologia e climatologia, ciências exatas e humanas; história brasileira da climatologia: clima como fenômeno geográfico; organização das escalas espacial e temporal do clima; características da atmosfera terrestre; interação entre elementos climáticos e fatores geográficos; circulação e dinâmica atmosférica; classificações climáticas e seus grandes domínios do mundo; climas do Brasil.

12 Ritmo, variabilidade e mudança no tempo-espaço; análise rítmica; climatologia aplicada à agricultura, saúde e cidade; Sistema Clima Urbano e seus canais de percepção humana; riscos e vulnerabilidades, impactos e desastres - natureza, sociedade e espaço; variabilidade climática e contexto regional; mudanças globais e climáticas: dinâmicas, agentes sociais, geopolítica; medidas de adaptação e mitigação.

${ }^{13} \mathrm{~A}$ alteridade deve ser um conceito-chave na prática docente, como forma de se desprender das próprias amarras pré-concebidas para desvendar e superar (UFVJM, 2018a) os estigmas sociais.
} 
Do período inicial ao final em estudo, os dados estatísticos sintetizam, por um lado, melhorias gerais na situação das turmas (Tabela 1). E parte dos resultados alcançados é procedente dessa reestruturação reflexiva da unidade curricular, mesmo que variáveis externas possam ter os influenciados de forma positiva ou negativa, por exemplo, composição heterogênea das turmas, dia de aula (sexta-feira como opção menos quista), calendário acadêmico, paralisações e greves, entre outras.

Tabela 1 - Situações da disciplina BHU416-Climatologia. UFVJM, 2014-2017

\begin{tabular}{cccccccc}
\hline \multirow{2}{*}{ SITUAÇÃo } & $\mathbf{2 0 1 4 - 2}$ & $\mathbf{2 0 1 5 - 1}$ & $\mathbf{2 0 1 5 - 2}$ & $\mathbf{2 0 1 6 - 1}$ & $\mathbf{2 0 1 6 - 2}$ & $\mathbf{2 0 1 7 - 1}$ & $\mathbf{2 0 1 7 - 2}$ \\
\hline $\begin{array}{c}\text { Aprovado } \\
\text { Reprovado por nota } \\
\text { insuficiente }\end{array}$ & $10 \%$ & $37,1 \%$ & $44,5 \%$ & $45,5 \%$ & $64,3 \%$ & $68 \%$ & $75 \%$ \\
$\begin{array}{c}\text { Reprovado por nota e } \\
\text { frequência insuficientes }\end{array}$ & $56,7 \%$ & $29,6 \%$ & $18,5 \%$ & $22,7 \%$ & $14,3 \%$ & $12 \%$ & $0 \%$ \\
\hline
\end{tabular}

Fonte: UFVJM, 2018b.

As porcentagens demonstram, com parâmetro na capacidade máxima da turma, o progressivo aumento das aprovações, com destaque para o primeiro período comparativo, de 2014 a 2015, o qual constata a incipiente preocupação docente em rever o planejamento didático desde à expressiva retenção inicial dos alunos (90\%). Em paralelo, a redução da reprovação por nota e frequência também teve seu auge em 2015-1, quando declinou o número de retidos em $41,2 \%$, seguido por $32,7 \%$ em $2016-2$, mas acrescido em $25 \%$ um ano depois. Ainda assim, este incremento precisa ser ponderado junto à reprovação apenas por nota no mesmo período, a qual foi reduzida a zero.

Já por semestre letivo, os extremos justificam a relevância de repensar a BHU416, por representarem a transformação completa da situação indesejada à almejada: da baixa à alta aprovação, da alta à baixa infrequência. Aliás, a considerável diminuição da reprovação por frequência induz avanços na atenção dos alunos acerca dos conteúdos climáticos, além de passarem a se reconhecer na dinâmica da unidade curricular, pois a desistência gradativa também era, ao longo das semanas, uma desistência simbólica do ensino-aprendizagem vigente. Em síntese, aquele ensino conteudista e abstrato foi ultrapassado pela busca por métodos criativos, inovadores e participativos, com o projeto de contextualizar temporo-espacialmente cada indivíduo com a vida cotidiana, a fim de produzir sentidos particulares na educação. Por isto, três práticas validadas e correntes na BHU416 serão pormenorizadas, por favorecerem meios de aprendizado significativos no ensino da Climatologia Geográfica, conjuntamente àqueles variados recursos e materiais didáticos utilizados.

\section{TECNOLOGIAS DIGITAIS DE INFORMAÇÃO E COMUNICAÇÃO}

Para Pimenta (2006, p. 19-20, grifo da autora), o "[...] conhecimento na ação é o conhecimento tácito, implícito, interiorizado, que está na ação e que, portanto, não a precede.". Na prática climatológica, constatou-se que somente a explicação oral e visual dos fenômenos atmosféricos não satisfaziam o processo 
de aprendizagem, devido a seu elevado grau de abstração. Diante de situações impremeditadas como esta apresentada, novas soluções didáticas precisam ser criadas pela (reflexão sobre a) reflexão na ação, em valorização da pesquisa na ação docente, denominada de professor pesquisador. Esta prática refletida pôde trazer as TDIC como modo de movimentar e articular a dinâmica atmosférica.

Com possibilidades e potencial enormes para mudar substancialmente a educação, as TDIC são uma das soluções para criar situações de aprendizagem que estimule a compreensão e construção de conhecimentos (VALENTE, 2014). $\mathrm{E}$, para isto, tais tecnologias precisam ser compreendidas pelo foco educacional, como seu uso na simulação de fenômenos.

As TDICs têm uma característica importante: a capacidade de animar objetos na tela. Com esse recurso, torna-se uma ferramenta essencial para complementar ou mesmo substituir muitas atividades desenvolvidas para o lápis e o papel. Na área de Ciências, por exemplo, muitos fenômenos podem ser simulados, permitindo o desenvolvimento de atividades ou a criação de um "Mundo do faz de conta", onde certas atividades não são passíveis de serem desenvolvidas no mundo real. (VALENTE, 2014, p. 151).

O Ambiente Virtual de Aprendizagem é um software que propicia oferta, organização e acompanhamento de conteúdos educacionais acessíveis pela rede virtual. Por meio deste sistema, a elaboração didática de certos conteúdos pode se enriquecer pela disponibilidade de múltiplas ferramentas ativas e interativas, que complementam a educação presencial. Sobre isto, Valente (2014, p. 146) confirmou que "a realização de tarefas por intermédio das TDICs apresenta características que são importantes para o processo de construção de conhecimento.", tanto dos aspectos cognitivos, pelo ciclo de ações descriçãoexecução-reflexão-depuração-nova descrição, quanto dos aspectos estéticos, pela combinação de textos, imagens e animação no lado emocional e afetivo do sujeito.

Disponibilizada gratuitamente pela UFVJM, a Plataforma Moodle permite a estruturação e o controle do ensino a distância ou semipresencial. No total de 15 h ( $20 \%$ da carga horária da unidade curricular), a oferta da BHU416 nesta plataforma é organizada em tarefas de até duas horas cada, com o total de oito blocos, que versam sobre assuntos vistos em sala de aula. Além de instruções específicas, fóruns e bibliografias das aulas, sua composição didática procura variar materiais e inclui pequenos textos científicos e reportagens em massa, animações audiovisuais, documentários e palestras. Como pode ser verificada, a Plataforma Moodle torna-se um ambiente que complementa a sala de aula, por abranger materiais incomuns e que costumam ocupar aquele tempo presencial mais destinado à relação direta professor-aluno. E para garantir a frequência da turma nessas atividades propostas, cada hora-aula é avaliada em um ponto, mediante algum registro textual solicitado em cada bloco, com prazo mínimo de duas semanas. Ademais, estas tarefas visam contemplar às diferentes rotinas do alunado, por transcenderem as inflexibilidades espacial e temporal do ensino presencial, traduzidas na padronização do local, dia e horário, e poderem se adequar a diversas peculiaridades que envolvem o dia a dia de cada um. 
Já em sala de aula, TDIC que viabilizam a relação simultânea entre teoria e prática são priorizadas. Antes de iniciar a aula, a projeção interativa da previsão do tempo, junto às devidas intervenções pedagógicas, exemplifica as condições da atmosfera naquele momento e local específicos, a qual facilita a associação instantânea da representação e realidade a partir da temperatura, da umidade, dos ventos etc. Em simples palavras, o aluno pode olhar para o tempo visto da janela e encontrar suas razões na projeção da dinâmica atmosférica, ou vice-versa. E para assegurar sua continuidade, este exercício é complementado com previsões estendidas, que são confirmadas ou não na semana seguinte. Essa ponte virtual-real, tão objetiva, clara e observável, corresponde a uma das aprendizagens mais significativas no ensino de climatologia.

Se trazidas para inovar, dinamizar e complementar a educação, as TDIC possuem vastas contribuições como novas ferramentas na mediação didática pelo professor. Mas tais tecnologias precisam ser integradas metodologicamente e referenciadas teoricamente, afinal, suas potencialidades não se encerram em trazer novidades modernas ao ensino tradicional. Por exemplo, o Sistema Clima Urbano, um conteúdo denso da Climatologia Geográfica, pode ser transposto didaticamente pela relação de seus diagramas - principal e dos subsistemas Termodinâmico, Físico-Químico e Hidrometeórico (MONTEIRO, 1976) - com um estudo de caso contemporâneo (atenção periódica ao insumo e a transformação por imagens de satélite, a produção e percepção por veículos de comunicação, a autorregulação por experiências exitosas divulgadas na rede virtual) ou histórico (correlação com documentários).$^{14}$

\section{PESQUISA DE CAMPO - ELEMENTOS CLIMÁtICOS E FATORES GEOGRÁFICOS}

Educação mnemônica é conhecida por ser aquela que objetiva alcançar o aprendizado de conteúdos imutáveis, impostos e incontestáveis pelo ensino. Ao término do percurso formativo, o "bom aluno" seria "[...] capaz de devolver o mesmo conteúdo, apresentado pelo professor, dos diferentes testes padronizados que enfrentará no decorrer do seu processo de escolarização." (GIROTTO, 2015, p. 239). Como alternativa ao conteudismo, a realidade precisa ocupar o centro do processo educativo.

Conforme Girotto (2015), a realidade atual deve ser o ponto de partida e chegada do ensino de Geografia para desenvolver/aprimorar um dos elementos fundantes do ser social, o raciocínio geográfico. Esta educação contextualizada possibiliza uma formação reflexiva, dialógica e interescalar entre mundo e lugar, que é enriquecida por experiências de vida dos sujeitos.

Nosso processo de constituição se dá em relação contínua de desenvolvimento de nossa percepção sobre a geografia dos objetos e sujeitos com os quais nos relacionamos diariamente. Nessa relação, vamos desenvolvendo capacidades que se referem à dimensão geográfica da realidade (situar, localizar,

\footnotetext{
${ }^{14}$ A título de exemplificação, "Entre rios - a urbanização de São Paulo" (2009) fornece elementos multidisciplinares suscetíveis de serem correlacionados ao Sistema Clima Urbano, principalmente seu subsistema Hidrometeórico.

Disponível em: <https://www.youtube.com/watch?v=Fwh-cZfWNIc>. Acesso em: 4 ago. 2018.
} 
correlacionar), qualificando assim a nossa experiência espaçotemporal. (GIROTTO, 2015, p. 233).

Por condicionarem a interação entre a atmosfera e a superfície terrestre, os elementos climáticos e fatores geográficos tornam-se conteúdos primordiais no ensino de climatologia, entretanto, o método verbal restrito em sala de aula tende a acentuar suas abstrações. No decurso dos períodos letivos, comprovouse, ora pelas explicações teóricas, ora pelas atividades avaliativas, a existência de sérias dificuldades das turmas em assimilar as propriedades e variações dos atributos físicos e, sobretudo, relacioná-las às características paisagísticas. Em vista disto, a realidade deve ser trazida para possibilitar a contextualização local e favorecer as experiências diretas dos alunos com o cotidiano, na junção metodológica do ativo ao verbal.

Situado numa extensa área verde, o Campus JK possui uma variedade de paisagens que diversificam os registros meteorológicos. Com o mínimo de cinco pessoas, os grupos escolhem e percorrem um dos trajetos propostos na UFVJM (Figura 1), com a finalidade de registrarem as temperaturas mínima e máxima $\left({ }^{\circ} \mathrm{C}\right)$, a umidade $(\%)$ e a pressão atmosférica $(\mathrm{mb})$, além de anotarem a altitude $(\mathrm{m})$, a forma de relevo, o tipo de vegetação e as atividades sociais (construções e circulação de veículos e indivíduos).

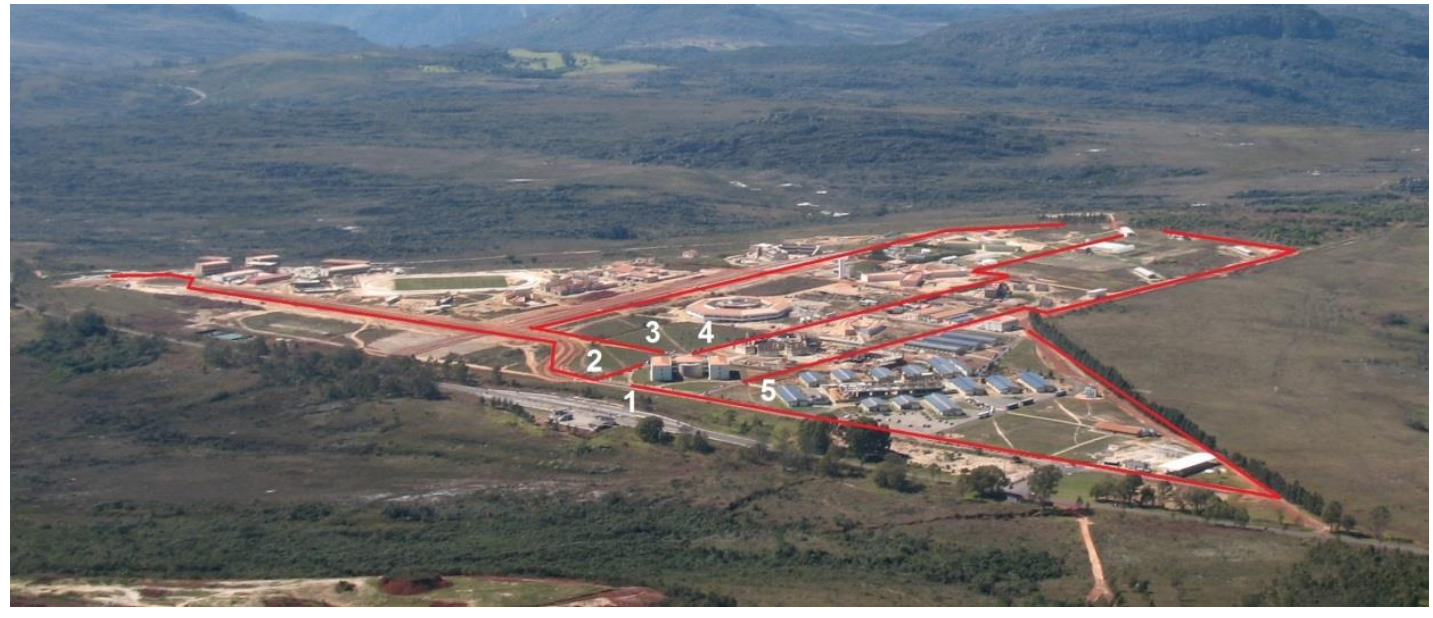

Figura 1 - Campus JK da UFVJM, em Diamantina-MG, e trajetos propostos para pesquisa de campo. Adaptada de: <http://mapeamento.ufvjm.edu.br/mapa_dtna/fotos_aereas/area_JK(45).jpg> .

Momentos antes do campo, as condições do tempo são apresentadas e explicadas a partir dos dados meteorológicos e da circulação atmosférica, com base em imagens por satélite e cartas sinóticas; aliás, esta ação didática de introduzir a prática de conteúdos inéditos na teoria, até então, tem trazido bons resultados no processo de aprendizagem. E, adiante, as formas de manusear os 
equipamentos são introduzidas na dinâmica (calibragem, posição, leitura, reset etc. ), ${ }^{15}$ juntamente ao repasse das instruções específicas sobre a ida ao campo.

Já sobre os trajetos, os cinco traçados representam apenas os sentidos geográficos do campo e, por isto, orienta-se cada grupo a procurar diferentes pontos de leitura, com recomendações como aproximar de árvores, optar por diferentes morfologias, adentrar em prédios, procurar aglomeração de pessoas e trânsito de veículos, entre outras. E quando um distinto ponto é selecionado para realizar o registro de dados e informações, recomenda-se um momento de espera para a estabilização dos instrumentos.

Como produto final, gráficos desenhados à mão sintetizam visualmente todas as leituras e observações feitas em campo (Figura 2). Em seus versos, variáveis são paralelamente analisadas pelo grupo e, ao longo do tempo, alguns resultados puderam ser levados para dentro da sala de aula: variações dentro do Campus JK de até $16 \mathrm{~m}$ de altitude, $1,5 \mathrm{mb}$ de pressão atmosférica, 6,3 oC de temperatura e $19 \%$ de umidade. A mais, os alunos comprovam, na prática, os decréscimos da pressão atmosférica e temperatura de acordo com a elevação da altitude; da queda da temperatura e do aumento da umidade na presença de vegetação; e, geralmente, do incremento térmico e das diminuições de umidade e ventos segundo as complexas atividades sociais.

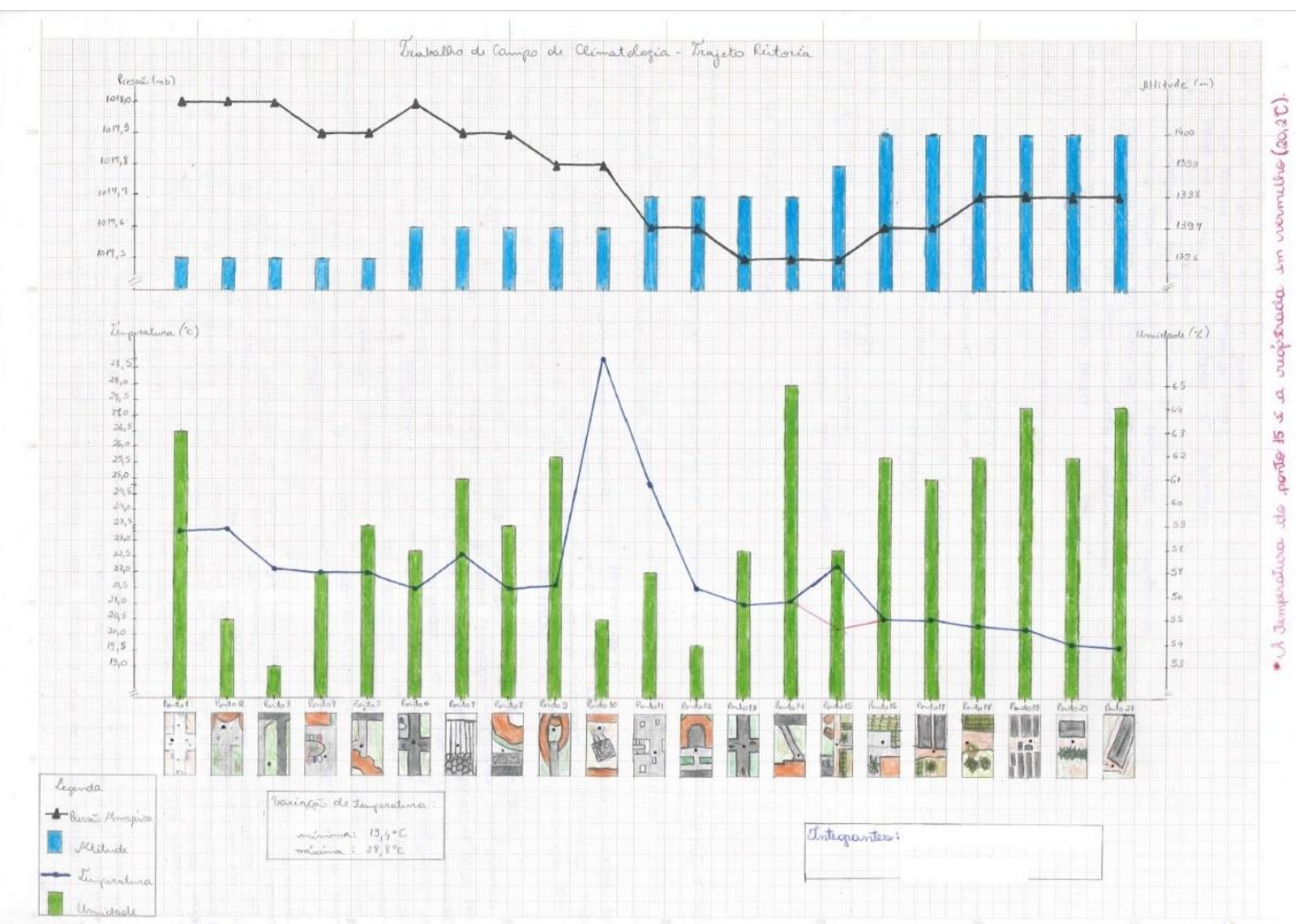

Figura 2 - Modelos de representação gráfica da pesquisa de campo na disciplina BHU416-Climatologia (UFVJM)

\footnotetext{
${ }^{15}$ Como alternativa na educação escolar, essa prática de campo pode, de certa forma, substituir a aquisição dos instrumentos meteorológicos pela construção da estação meteorológica artesanal. Disponível em: <https://drive.google.com/open?id=0B20jgPRdnT_JWG9GS25IbE1iOUE > . Acesso em: 15 ago. 2018.
} 


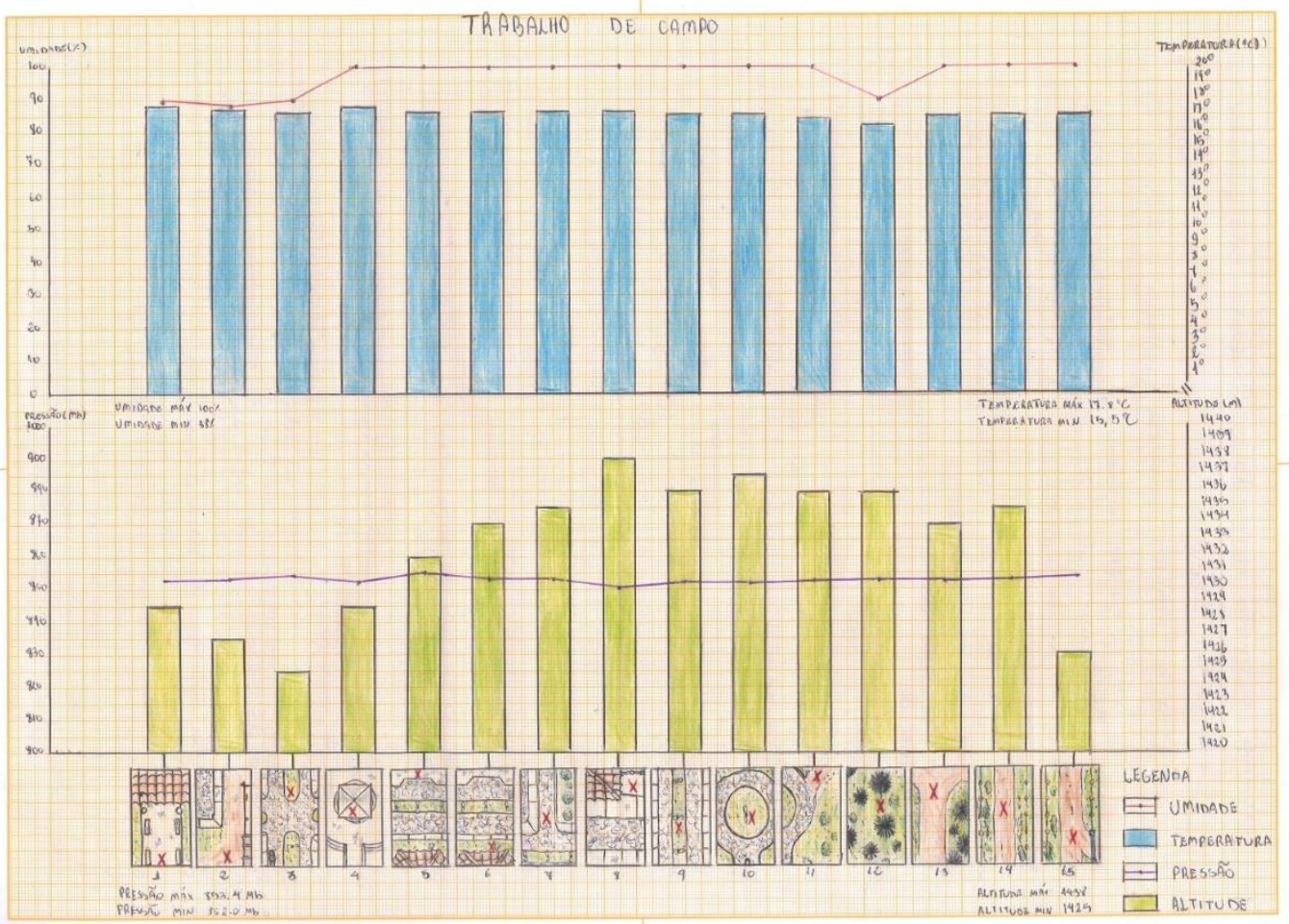

Figura 2 - Modelos de representação gráfica da pesquisa de campo na disciplina BHU416-Climatologia (UFVJM). Arquivo próprio, 18 maio 2016; 1 dez. 2017 (entre 20 h e $22 \mathrm{~h})$.

Entende-se que a Climatologia Geográfica parte do tratamento geográfico nos estudos atmosféricos, com análises originais sobre o espaço social sob o ângulo da dinâmica climática. Para isto, considerar o clima como fenômeno geográfico requer considerar toda a complexidade espacial das relações sociais, junto à cadência rítmica de sucessão dos tipos de tempo. A pesquisa de campo a respeito de elementos e fatores conseguiu pluralizar uma superfície terrestre vista como monótona apenas no primeiro momento, revelando como suas paisagens heterogêneas se interagem com a atmosfera próxima. E questões que abrangem o planejamento territorial da Universidade, por exemplo, a forma de expansão da infraestrutura, a verticalização construtiva, os tipos de materiais, os revestimentos do solo, a dispersão arbórea, as legislações ambientais, a mobilidade e acessibilidade, entre muitas outras, puderam ser associadas e investigadas no debate climático com os alunos. Já sobre a noção de ritmo, a próxima prática ficará a cargo de complementar a assimilação do conhecimento na área da Climatologia Geográfica.

\section{ANÁLISE RÍTMICA: UMA PRÁTICA GEOGRÁFICA NA CLIMATOLOGIA}

De modo a aprender "ferramentas", assim elucidadas por Alves (2008), ensinar análise rítmica equivale apresentar, reforçar e difundir uma proposta metodológica que dinamiza as relações atmosfera-superfície terrestre. Neste instante, os elementos climáticos são interagidos entre si e combinados com as células regionais da circulação atmosférica, numa sequência que conduz ao 
ritmo - a essência da análise dinâmica (MONTEIRO, 1969). Enquanto este novo paradigma torna o ensino de climatologia mais atraente e geográfico e menos aborrecido e estático, para Monteiro (1999), o ritmo climático passa a produzir novos sentidos na educação, por permitir o aluno a acompanhar, compreender e correlacionar os movimentos da atmosfera no dia a dia.

[...] assim como a palavra para Freire serve para ler o mundo, o conjunto de saberes construídos na educação geográfica só tem sentido se for capaz de mudar a forma dos educandos e educandas de ver e agir no mundo em suas diferentes escalas espaços-temporais. (GIROTTO, 2015, p. 238).

Ao contestar a compreensão do clima preconizada por Julius Hann (18391921), que o considerava como o estado médio dos elementos atmosféricos sobre o dado lugar, e a classificação climática global de Wladimir Köppen (18461940), pelo empirismo das técnicas utilizadas e pela impossibilidade de definir estatisticamente a dinamicidade da atmosfera, Maximilien Sorre (1880-1962) propôs a noção de ritmo por meio do complexo climático (meio climático), com o argumento que apenas o ritmo da sucessão dos tipos de tempo expressaria, globalmente, a variabilidade climática de determinado lugar.

As definições clássicas dão importância exagerada à noção de valores médios. Propusemos substituí-lo por uma fórmula mais diretamente utilizável pelos biólogos: o clima, num determinado local, é a série de estados da atmosfera, em sua sucessão habitual. E o tempo que faz nada mais é do que cada um desses estados considerado isoladamente. Essa definição conserva o caráter sintético da noção de clima, enfatiza seu aspecto local e, ao mesmo tempo, evidencia o caráter dinâmico do clima, introduzindo as idéias de variação e de diferenças incluídas nas de sucessão. (SORRE, 1984, p. 32).

Considerado o mentor intelectual de uma Climatologia eminentemente geográfica, por ter extraído um novo paradigma a partir da essência dinâmica e genética do clima sem estudo empírico (SANT'ANNA NETO, 2004), Max. Sorre possibilitou entender o desempenho da atmosfera como fenômeno geográfico, pelas noções de dinâmica, gênese e ritmo. E apoiado nesta concepção sorreana e na crítica de Pierre Pédélaborde (1911-1992), Carlos Augusto de F. Monteiro propôs uma mudança de paradigma na abordagem geográfica do clima, por meio do ritmo de sucessão habitual dos estados atmosféricos sobre os lugares.

A aceitação do conceito de Max Sorre (1951) deu margem a adoção de um novo paradigma que não encontraria apoio em uma estratégia metodológica, de vez que Sorre não produziu análises climatológicas. A estratégia proposta por Pédélaborde (1957) foi descartada, de vez que ele se preocupava antes com o levantamento da "totalidade dos tipos de tempo", enquanto a mim interessava mais o mecanismo "seqüencial" desses tipos, dando atenção às suas peculiares irregularidades, posto que estas se constituem (longe de ser "exceções") em eventos de 
imensa importância aos processos de interação geográfica. (MONTEIRO, 1991, p. 38-39).

Com fins metodológicos, Monteiro (1971) apresentou a análise rítmica para revelar, em nível diário e regional do tempo, a gênese dos fenômenos climáticos pela interação de elementos e fatores. Os parâmetros resultantes destas análises episódicas devem considerar desde as particularidades espaciais entre objetos e ações até os impactos gerados durante eventos irregulares, que fogem do estado normal do clima e são capazes de produzir efeitos adversos no cotidiano geográfico. $\mathrm{E}$, para tanto, aquela climatologia restringida à média não atende a Climatologia Geográfica, uma vez que oculta valores extremos que são, justamente, os mais relevantes para o planejamento e a gestão territorial, regional, ambiental, agrícola, urbano.

Na sala de aula, a análise rítmica apresenta-se como um meio prático de juntar e trabalhar vários conteúdos numa só oportunidade. O estudo simultâneo dos elementos climáticos e mecanismos atmosféricos beneficia esclarecer suas relações e gêneses, pois ajuda o aluno a assimilar as inter-relações da pressão atmosférica, temperatura, umidade, precipitação, direção e velocidade do vento e nebulosidade; os estados meteorológicos na passagem de uma frente fria; as influências prolongadas da Zona de Convergência do Atlântico Sul; as distintas atuações das massas de ar etc., além dele poder interpretar cientificamente o tempo observado na semana anterior. Assim, esta análise conjunta possui um potencial didático que permite explorar aprendizados significativos no ensino de climatologia e, também, de Geografia, quando associada a casos de riscos e vulnerabilidades e suas consequências socialmente diferenciadas em eventos de chuvas intensas, contínuas ou escassas, temperatura e umidade altas ou baixas, ventos fortes ou calmarias.

\section{CONSIDERAÇÕES FINAIS}

Em sua Obra, Freire (2011) alertou sobre a grande responsabilidade do professor, ainda que a sociedade não se dê conta, e pontuou características que devem estar presentes em sua prática eminentemente formadora. Entre estas, a reflexão crítica acerca da própria prática docente levou a entender que ensinar não significava transferir conhecimento, mas sim, criar possibilidades para sua construção. Logo, o comprometimento profissional buscou reformular o ensino de climatologia pela curiosidade discente na apreensão da realidade, já que a memorização mecânica de conteúdo não condiz com o aprendizado verdadeiro "neste caso, o aprendiz funciona muito mais como paciente da transferência do objeto ou do conteúdo do que como sujeito crítico, epistemologicamente curioso, que constrói o conhecimento do objeto ou participa de sua construção." (FREIRE, 2011, p. 67).

Esse caminho didático visou basicamente superar o ensino de Geografia conteudista e abstrato pela aprendizagem em torno da realidade, sob diferentes escalas. Para proporcionar maior assimilação de conhecimentos na BHU416, em consideração às especificidades dos cursos e do público atendido, a mediação pedagógica encontrou na Climatologia Geográfica meios epistemológicos para aproximar a subárea Física da Humana, as dinâmicas naturais das sociais, a prática da teoria, a quantidade da qualidade, enfim, romper com as antigas 
"atividades antrópicas" e entendê-las a partir das desiguais relações sociais na produção do espaço e sua interação com o ritmo climático.

Sabe-se que bons resultados no processo de ensino-aprendizagem não se limitam ao planejamento da ação didática, nem melhorias na situação final das turmas são efeitos exclusivos da prática docente. Educação envolve relações humanas e corresponsabilidades coletivas. "Trata-se do fato irrecusável de que o ensino e a aprendizagem se dão como e resultam de uma relação social, de um conjunto de interações humanas, portanto, que não se podem resumir a simples procedimentos técnicos isolados." (CORDEIRO, 2010, p. 98, grifos do autor). Ainda assim, não se pode deixar de reconhecer o mérito das propostas discutidas nos resultados apresentados. E para complementá-los, as avaliações institucionais mostram aumento geral de 48,5\% de 2014/2 a 2017/2 e médio de $7,2 \%$ a cada período letivo na avaliação da BHU416 (UFVJM, 2018b), à medida que as informais, como feedbacks públicos realizados no último dia de aula, se resumem em três tópicos: 1) insuficiência da carga horária da unidade curricular perante sua ementa prevista, que resulta em muitos conteúdos; 2) destaques das práticas de campo e análise rítmica na construção do conhecimento; e 3) diversidade das avaliações realizadas, por contemplarem as diversas faculdades humanas.

Junto à pesquisa e extensão, o ensino representa um importante pilar na formação acadêmica. E pelo fato do corpo docente das universidades brasileiras ser constituído por profissionais titulados e altamente capacitados em sua área de conhecimento, mas nem sempre com competência na área pedagógica, pois o que importa para ser professor é dominar e transmitir conteúdos atualizados com profundidade (MASETO, 2003), o presente artigo se faz importante nesta perspectiva, até porque não são comuns trabalhos sobre a docência no ensino superior. A formação autorreflexiva, pela dita reflexão na ação que valoriza a pesquisa na atividade docente, deve amparar o cargo de Professor na Carreira do Magistério Superior, sobretudo num curso de licenciatura. E a reflexividade é a base deste trabalho, mas não como roteiro a ser seguido, afinal, como lembrou Freire (2011), o espaço pedagógico é um texto a ser constantemente "lido", interpretado, "escrito" e "reescrito" pela solidariedade particular entre educador e educandos.

\section{AGRADECIMENTOS}

Neste momento reflexivo, recordo e agradeço à Geografia da Faculdade de Ciências e Tecnologia, Universidade Estadual Paulista (Campus de Presidente Prudente), por toda a formação acadêmica. Por esses brasis, aquela Geografia crítica, por um lado, e dinâmica/complexa, por outro, tornou-se um diferencial agregador entre conhecimentos demasiadamente técnicos ou individualistas, tão apáticos ou egoístas, no meio geográfico.

\section{REFERÊNCIAS}

ALVES, R. Por uma educação romântica. 7. ed. Campinas: Papirus, 2008.

AMORIM, M. C. C. T.; NUNES, J. O. R. Geografia e ambiente: reflexões sobre o atual momento da geografia física. Geografia, Rio Claro, v. 31, n. 2, p. 427-432, 2006. 
BRASIL. Ministério da Educação. Secretaria de Educação Superior. Referenciais orientadores para os bacharelados interdisciplinares e similares. Brasília, DF: MEC/SESu, 2010.

CALLAI, H. C. Geografia: um certo espaço, uma certa aprendizagem. 1995. 294 f. Tese (Doutorado em Geografia Física) - Faculdade de Filosofia, Letras e Ciências Humanas, Universidade de São Paulo, São Paulo, 1995.

CORDEIRO, J. Didática. 2. ed. São Paulo: Contexto, 2010.

FREIRE, P. Pedagogia da autonomia: saberes necessários à prática educativa. 43. ed. São Paulo: Paz e Terra, 2011.

GIROTTO, E. D. Formando leitores do mundo: algumas considerações sobre o ensino de Geografia no mundo contemporâneo. Boletim Campineiro de Geografia, Campinas, v. 5, n. 2, p. 231-247, 2015.

HAYDT, R. C. C. Curso de didática geral. 8. ed. São Paulo: Ática, 2006.

LIBÂNEO, J. C. Didática. São Paulo: Cortez, 1990.

MAIA, C. M. S.; SCHEIBEL, M. F.; URBAN, A. C. (Org.). Didática: organização do trabalho pedagógico. Curitiba: IESDE Brasil, 2009.

MASETO, M. T. Docência universitária: repensando a aula. In: TEODORO, A.; VASCONCELOS, M. L. (Org.). Ensinar e aprender no ensino superior: por uma epistemologia da curiosidade na formação universitária. São Paulo: Cortez, 2003, p. 79-124.

MENDONÇA, F.; DANNI-OLIVEIRA, I. M. Climatologia: noções básicas e climas do Brasil. São Paulo: Oficina de Textos, 2007.

MONTEIRO, C. A. F. A frente polar atlântica e as chuvas de inverno na fachada sul-oriental do Brasil (contribuição metodológica à análise rítmica dos tipos de tempo no Brasil). São Paulo: IGEOG/USP, 1969. (Série Teses e Monografias, 1).

- Análise rítmica em climatologia - problemas da atualidade climática em São Paulo e achegas para um programa de trabalho. Climatologia 1, São Paulo, n. $1,1971$.

. Teoria e clima urbano. São Paulo: IGEOG/USP, 1976. (Série Teses e Monografias, 25).

- Clima e excepcionalismo: conjecturas sobre o desempenho da atmosfera como fenômeno geográfico. Florianópolis: Ed. UFSC, 1991.

1, maio 1999.

. O estudo geográfico do clima. Cadernos Geográficos, Florianópolis, n.

MORAES, A. C. R. Geografia: pequena história crítica. São Paulo: Hucitec, 1983.

PIMENTA, S. G. Professor reflexivo: construindo uma crítica. In:

GHEDIN, E. (Org.). Professor reflexivo no Brasil: gênese e crítica de um conceito. 4. ed. São Paulo: Cortez, 2006, p. 17-52.

SANT'ANNA NETO, J. L. História da climatologia no Brasil - gênese e paradigmas do clima como fenômeno geográfico. Cadernos Geográficos, Florianópolis, n. 7, maio 2004.

SANTOS, M. A natureza do espaço. Técnica e tempo. Razão e emoção. São Paulo: Hucitec, 1996. 
SORRE, M. A adaptação ao meio climático e biossocial - geografia psicológica. In: MEGALE, J. F. (Org.). Max. Sorre: Geografia. São Paulo: Ática, 1984, p. $30-$ 86. (Coleção Grandes Cientistas Sociais, 46).

SUERTEGARAY, D. M. A.; NUNES, J. O. R. A natureza da geografia física na geografia. Terra Livre, São Paulo, n. 17, p. 11-24, 2001.

UFVJM. Pró-Reitoria de Graduação. Diretoria de Ensino. Projeto político pedagógico do curso de graduação em Humanidades - bacharelado. Diamantina, 2011.

- Pró-Reitoria de Graduação. Diretoria de Ensino. Projeto pedagógico do curso de graduação em Geografia - licenciatura. Diamantina, 2018a.

. Pró-Reitoria de Graduação. Diretoria de Registro e Controle Acadêmico. Banco de dados SIGA - módulo ensino. Diamantina, 2018b.

VALENTE, J. A. A comunicação e a educação baseada no uso das tecnologias digitais de informação e comunicação. Revista UNIFESO - Humanas e Sociais, Teresópolis, v. 1, n. 1, p. 141-166, 2014. 